\title{
Platform effects on optical variability and prediction of underwater visibility
}

\author{
Grace Chang, ${ }^{1, \star}$ Michael S. Twardowski, ${ }^{2}$ Yu You, ${ }^{3}$ Mark Moline,,${ }^{4}$ Peng-wang Zhai, ${ }^{5}$ \\ Scott Freeman, ${ }^{2}$ Matthew Slivkoff, ${ }^{2}$ Francesco Nencioli, ${ }^{6}$ \\ and George W. Kattawar ${ }^{3}$ \\ 'Sea Engineering, Incorporated, 200 Washington Street, Suite 210, Santa Cruz, California 95060, USA \\ ${ }^{2}$ WET Labs, Incorporated, Department of Research, 70 Dean Knauss Drive, \\ Narragansett, Rhode Island 02882, USA \\ ${ }^{3}$ Texas A\&M University, Department of Physics, 4242 TAMU, College Station, Texas 77843, USA \\ ${ }^{4}$ California Polytechnic State University, San Luis Obispo, California 93407, USA \\ ${ }^{5}$ Science Systems and Applications, Incorporated, 1 Enterprise Parkway Suite 200, \\ Hampton, Virginia 23666, USA \\ ${ }^{6}$ University of California, Santa Barbara, Santa Barbara, California 93106, USA \\ ${ }^{*}$ Corresponding author: gchang@ @eaengineering.com
}

Received 15 January 2010; revised 8 April 2010; accepted 12 April 2010; posted 21 April 2010 (Doc. ID 122668); published 12 May 2010

\begin{abstract}
We present hydrographic and optical data collected concurrently from two different platforms, the R/P FLoating Instrument Platform and the R/V Kilo Moana, located about $2 \mathrm{~km}$ apart in the Santa Barbara Channel in California. We show that optical variability between the two platforms was due primarily to platform effects, specifically the breakdown of stratification from mixing by the hull of R/P FLIP. Modeled underwater radiance distribution differed by as much as $50 \%$ between the two platforms during stratified conditions. We determine that the observed optical variability resulted in up to $57 \%$ differences in predicted horizontal visibility of a black target. (C) 2010 Optical Society of America

OCIS codes: $\quad 010.7295,010.4450$.
\end{abstract}

\section{Introduction}

Successful, rapid identification of underwater targets and accurate underwater imaging are critical for many environmental monitoring, commercial, and military [e.g., special operations and mine warfare, such as mine countermeasure (MCM) procedures] operations. Traditional underwater identification methods employ divers. New-generation optical identification techniques for use on remotely operated vehicles or other autonomous vehicles are being explored to facilitate and automate underwater target identification. For effective deployment and

0003-6935/10/152784-13\$15.00/0

(C) 2010 Optical Society of America interpretation, divers and other underwater vision systems require environmental optical conditions reconnaissance before deployment to predict and optimize asset performance.

Optical properties have direct application in predicting the performance of underwater imaging assets and for specifying key deployment parameters in underwater imaging and, e.g., MCM operations. Performance prediction usually involves estimating a probability of detection or probability of identification as a function of operational parameters. Performance optimization for these assets could range from (a) adjusting operational parameters to optimize chances of detection, to (b) helping determine the most effective asset for a given set of conditions, or 
(c) making the determination that any asset deployment would be ineffective.

The prediction of the ability of some observer to detect an object in a given environment is directly related to the underwater radiance distribution and the attenuation of light [1-3]. Accurate resolution of the inherent and apparent optical properties (IOPs, properties that are dependent only on the aquatic medium itself, and AOPs, properties that depend on the IOPs and the ambient light field and its geometrical distribution) is thus essential to predictions of visibility and underwater imaging analysis (e.g., see $[\underline{4}, \underline{5}])$.

\section{A. Background}

We present data collected as part of Radiance in a Dynamic Ocean (RaDyO), an Office of Naval Research-sponsored program dedicated to the study of light propagation and imaging as affected by upper-ocean and atmospheric dynamics. The specific goals of $\mathrm{RaDyO}$ are to

- Examine time-dependent oceanic radiance distribution in relation to dynamic surface boundary layer (SBL) processes.

- Construct a radiance-based SBL model.

- Validate the model with field observations.

- Investigate the feasibility of inverting the model to yield SBL conditions.

Three field experiments were executed as part of RaDyO: Scripps Institution of Oceanography Pier, California, in January 2008; Santa Barbara Channel, California, in September 2008; and south of the Big Island, Hawaii, in August and September 2009. The latter two experiments involved measurements of atmospheric and upper-ocean physical properties from R/P FLoating Instrument Platform (FLIP) and measurements of IOPs and AOPs from
R/P FLIP and the R/V Kilo Moana (KM), located nearby. An autonomous underwater vehicle (AUV), Remote Environmental Measuring UnitS (REMUS100), provided physical and optical data at high spatial resolution for both experiment sites.

The R/P FLIP was chosen for its stability on the open sea, a criterion necessary for small-scale SBL measurements. The R/P FLIP is a $108 \mathrm{~m}$ long manned spar buoy designed as a stable research platform for oceanographic research. It is towed to its operating site in the horizontal position and then flipped to the vertical position through ballast changes. At its vertical configuration, it is a stable spar buoy with a draft of approximately $91 \mathrm{~m}$; the diameter of its hull from the 91 to $49 \mathrm{~m}$ depth is $6.5 \mathrm{~m}$, tapering to $4 \mathrm{~m}$ at the $20 \mathrm{~m}$ depth. R/P FLIP can operate either in moored or drifting mode. It can accommodate a science party of only up to 11 people, hence the need for a second research vessel, the Kilo Moana, during the $\mathrm{RaDyO}$ experiments.

Our objectives here are to determine (a) the differences, if any, between optical properties and optical variability measured from the R/P FLIP and from the $\mathrm{R} / \mathrm{V}$ Kilo Moana (hereafter referred to as FLIP and $\mathrm{KM}$ ) and (b) the effects of optical variability on the modeling of the underwater radiance distribution and horizontal visibility (i.e., diver visibility).

\section{Methods}

We focus on data collected concurrently from FLIP and $\mathrm{KM}$ during the second $\mathrm{RaDyO}$ field experiment in the Santa Barbara Channel in September 2008 [Fig. 1, Table 1]. The FLIP was moored off Santa Barbara, California $\left(34^{\circ} 12^{\prime} 18^{\prime \prime} \mathrm{N}, 119^{\circ} 37^{\prime} 44^{\prime \prime} \mathrm{W}\right)$, using a two-point mooring. The KM was located approximately $1.85 \mathrm{~km}$ north of FLIP at approximately $34^{\circ} 13^{\prime} 12^{\prime \prime} \mathrm{N}, 119^{\circ} 37^{\prime} 58^{\prime \prime} \mathrm{W}$ over the time periods of data collection [Fig. 1]. The REMUS operated in a

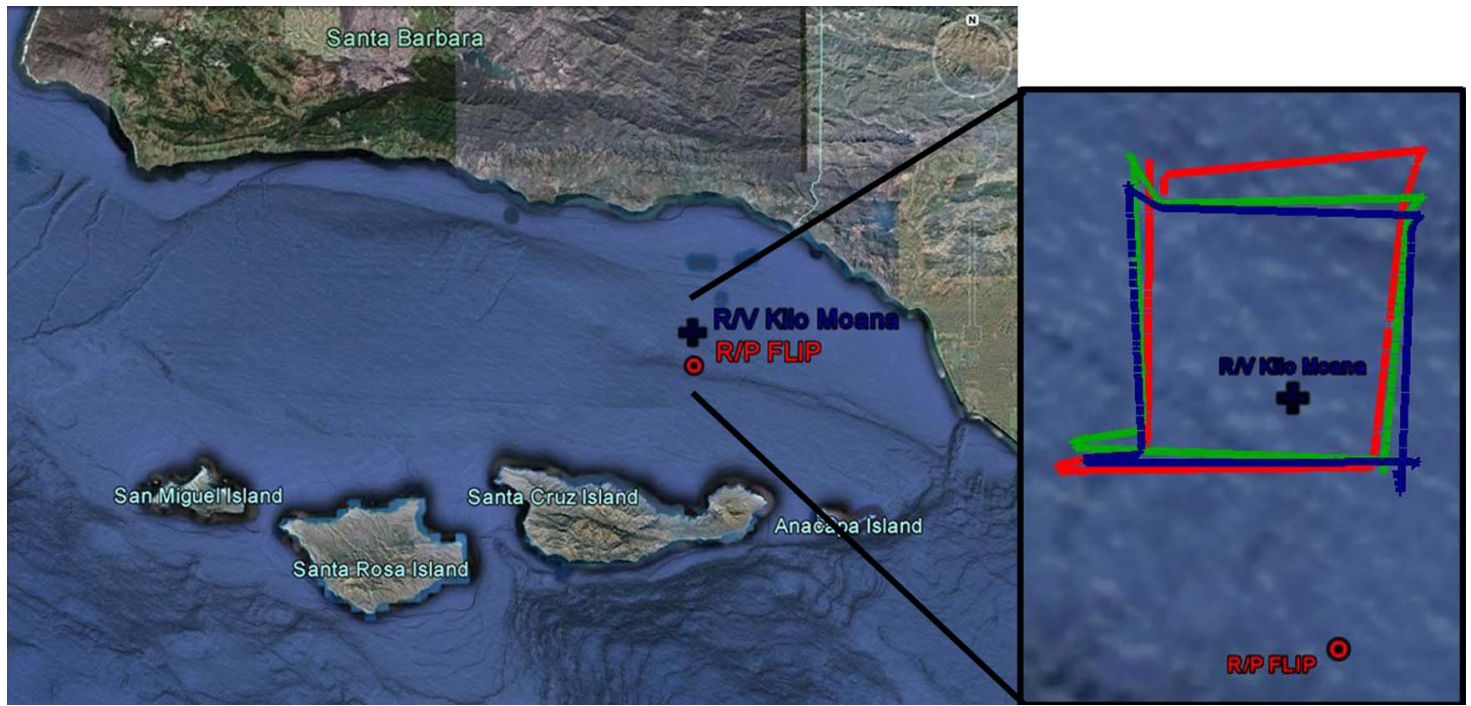

Fig. 1. (Color online) Map of the Santa Barbara Channel, California, USA, with locations of the R/V Kilo Moana (plus) and R/P FLILP (circle) indicated. The inset shows the platform locations with AUV tracks beginning on 14 September at 08:27, 15 September at 07:08, and 15 September at 11:04. 
box pattern around the KM for two days in September 2008. The water depth was about $175 \mathrm{~m}$.

Instrumentation packages were deployed in profile mode from each platform several times per day. Profiles from FLIP were conducted to a depth of about $30 \mathrm{~m}$, whereas the depth of profiles from KM was more variable, ranging from 20 to $150 \mathrm{~m}$. The relevant instrumentation and properties measured from both platforms included (a) Sea-Bird Electronics, Incorporated, SBE49 FastCAT for conductivitytemperature-depth (CTD), (b) WET Labs, Incorporated, absorption-attenuation meter for absorption, attenuation, and scattering (by difference) coefficients at 9 (KM; ac-9) or 87 wavelengths (FLIP; ac-s), (c) WET Labs, Incorporated, ECO-bb for backscattering coefficient at three (KM; ECObb-3) or nine wavelengths (FLIP; ECObb-9), and (d) Sequoia Scientific, Incorporated, Laser In Situ Scattering and Transmissometry (LISST-100X) type B (KM) or type C (FLIP) for near-forward volume scattering function (VSF) at 32 log-spaced bins. The ac-9 and ac-s are referenced to pure water; therefore, their output is particulate plus dissolved absorption, attenuation, and scattering coefficients, $a_{p g}(\lambda), c_{p g}(\lambda)$, and $b_{p}(\lambda)$, respectively, where $\lambda$ denotes wavelength dependence (assuming the dissolved matter does not scatter). Additionally, an ac-9 fitted with a $0.2 \mu \mathrm{m}$ filter was deployed from the FLIP for measurements of the dissolved absorption coefficient, $a_{g}(\lambda)$. The KM ac-9 sampling routine, at times, included determination of $a_{g}(\lambda)$ by use of a $0.2 \mu \mathrm{m}$ filter.

Individual profiles from each platform (Table 1) were processed in a similar manner, outlined here. Raw data were converted to engineering units, and optical data were merged with CTD data using the WET Labs, Incorporated, Data Handler (DH-4).
Using The MathWorks MATLAB software, the following processing steps were followed: (a) all data were binned to $0.25 \mathrm{~m}$ depth, (b) $a_{g}(\lambda)$ data were corrected for the time lag associated with use of the $0.2 \mu \mathrm{m}$ filter (when $a_{g}(\lambda)$ measurements were available), (c) $a_{g}(\lambda), a_{p g}(\lambda)$, and $c_{p g}(\lambda)$ data were corrected for temperature and salinity effects $[6,7]$ and for instrumental drift (if any), (d) $a_{p g}(\lambda)$ was corrected for scattering effects [8], (e) backscattering coefficients, $b_{b p}(\lambda)$, were computed from measured total VSF, $\beta_{t}$, at $117^{\circ}$ [9-11], (f) the spectral slope of $a_{g}(\lambda)$ was determined using the classical exponential relationship (e.g., see [2]) and the hyperbolic model presented by Twardowski et al. [12], (g) $a_{g}(\lambda)$ was subtracted from $c_{p g}(\lambda)$ to derive the spectral particle attenuation coefficient, $c_{p}(\lambda)$, (h) the slope of the $c_{p}(\lambda)$ spectrum, $\gamma$, an indicator of particle size distribution, was estimated [13], (i) the real part of the index of refraction of particles, $n_{p}$, was derived following methods described by Twardowski et al. [14], (j) density, $\sigma_{t}$, was computed from measured temperature and salinity, based on the standard developed by UNESCO (e.g., see [15]), (k) the mixed layer depth (MLD) was computed using a $0.5 \mathrm{~m}$ temperature criterion, and (l) the thermocline, halocline, and pycnocline depths were estimated based on maximum deviations in temperature, salinity, and density, respectively, over intervals of $1.0 \mathrm{~m}$ within the top $30 \mathrm{~m}$ of the water column.

The datasets from the two platforms were then merged with depth and density and compared. The ac-s and ECObb-9 measurements from FLIP were linearly interpolated to the KM ac-9 and ECObb-3 wavelengths, respectively. Wavelength differences were less than $3 \mathrm{~nm}$ in all cases with the exception of $b_{b}(488)$ (bb-9) and $b_{b}(470)$ (bb-3); therefore,

Table 1. Relevant R/P FLIP, R/V KM, and REMUS-100 AUV Dates, Times, Depths, and Parameters Collected During the 2008 Santa Barbara Channel RaDyO Field Experiment

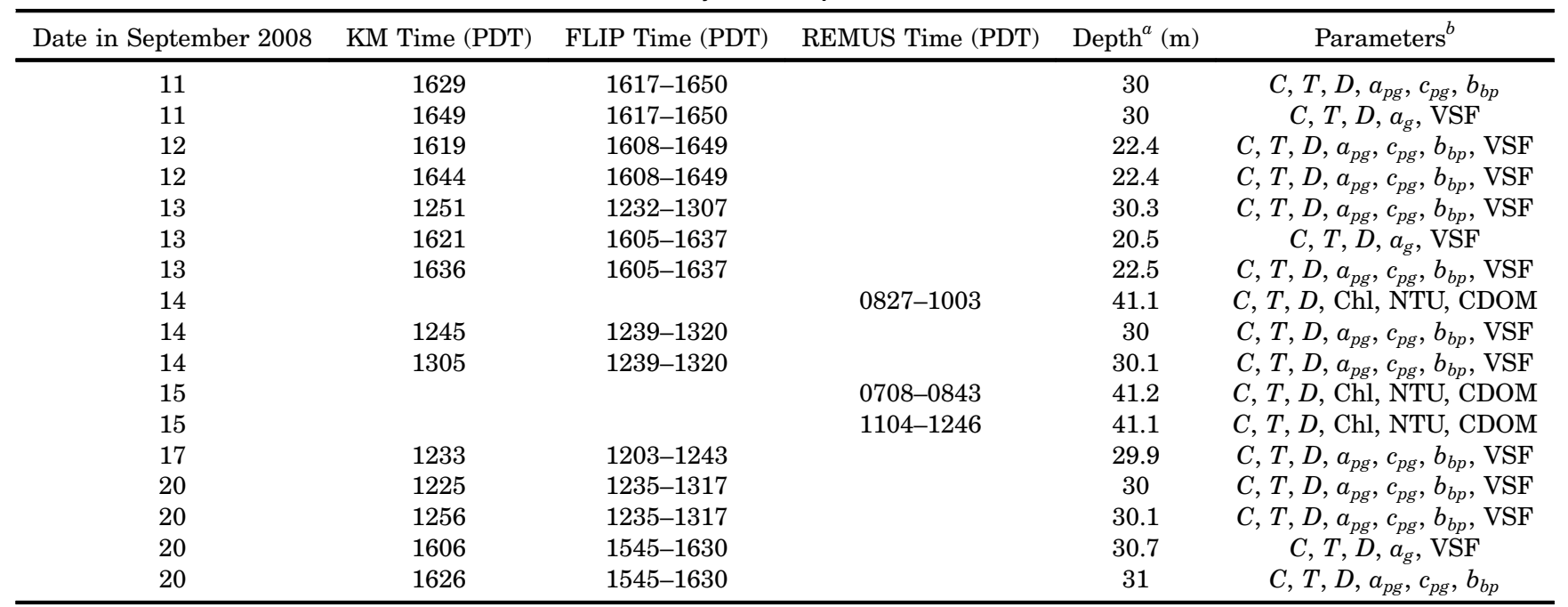

\footnotetext{
${ }^{a}$ Maximum profile depth of measurements made from either KM or FLIP or of the AUV.

${ }^{b} C$, conductivity; $T$, temperature; $D$, depth; $a_{p g}$, spectral particulate plus dissolved absorption coefficient; $c_{p g}$, spectral particulate plus dissolved attenuation coefficient $b_{b p}$, spectral particulate backscattering coefficient; $a_{g}$, spectral dissolved absorption coefficient; Chl, chlorophyll $a$ concentration; NTU, nephelometric turbidity units; CDOM, colored dissolved organic matter concentration.
} 
minimal errors were introduced by interpolation. Profiles measured from the KM were binned to $0.5 \mathrm{~m}$, and the profiles measured from FLIP were interpolated to depth and $\sigma_{t}$ derived from KM CTD profiles. Percent differences between measurements from the KM and FLIP were computed according to

$$
\begin{aligned}
\% \text { Difference }= & {\left[\left(X_{\mathrm{KM}}-X_{\mathrm{FLIP}}\right) /\left(X_{\mathrm{KM}}+X_{\mathrm{FLIP}}\right) / 2\right] } \\
& * 100,
\end{aligned}
$$

where $X$ is temperature, salinity, $a_{g}(\lambda), a_{p g}(\lambda), c_{p g}(\lambda)$, $b_{b p}(\lambda), \gamma$, or $\left(1-n_{p}\right)$ as a function of depth and as a function of $\sigma_{t}$.

Ancillary time series data were collected by instrumentation mounted on the KM and FLIP. We present wind speed data at $10 \mathrm{~m}$ above sea level (R.M. Young anemometer) and current meter data at $17 \mathrm{~m}$ water depth [Teledyne RD Instruments acoustic Doppler current profiler (ADCP); $300 \mathrm{kHz}$ Workhorse], both measured from the KM. Wind speeds and currents were corrected for vessel speed. Additionally, the WET Labs, Incorporated, Water Quality Monitor (WQM) was mounted on the hull of the FLIP at $30 \mathrm{~m}$. The WQM provided time series of temperature, salinity, chlorophyll fluorescence, and turbidity.

\section{A. Autonomous Underwater Vehicle}

A REMUS-100 AUV (Hydroid, Incorporated) was used in this study to help define the spatial distribution of physical and optical properties of the water column within the RaDyO study site. The AUV was deployed on the fourteenth and fifteenth of August 2008 (Table 1), approximately $1 \mathrm{~km}$ from the KM. It was programmed to collect data at 4 knots in both a constant depth mode and an undulating mode between 3 and $40 \mathrm{~m}$ in a box pattern around the KM [Fig. 1, inset]. Twenty-eight undulating profiles were conducted during each of the three box pattern traverses around the KM, for a total of 84 profiles.

The REMUS AUV is a propeller-driven platform that, in this study, navigated by compass while underwater with consistent surface global positioning system fixes on the corners of the boxes. While the vehicle occasionally deviated up to $200 \mathrm{~m}$ from the planned path because of strong currents, it did not influence the objective of examining the variability in the physical and optical parameters in the area. For this study, the REMUS was configured with a Teledyne RD Instruments $1200 \mathrm{kHz}$ upward- and downward-looking Workhorse ADCP; a Neal Brown, Incorporated, conductivity-temperature (CT) sensor; a WET Labs, Incorporated, ECO Triplet for turbidity, chlorophyll fluorescence, and colored dissolved organic matter (CDOM) fluorescence; and Satlantic, Incorporated, OCR-507 spectral irradiance and radiance sensors for measuring upwelling and downwelling light fields. A complete description of this vehicle, navigational capabilities, and applications in scientific studies are detailed elsewhere [16-23].

\section{B. Modeling}

Several models were employed to investigate the effects of IOP variability on the underwater radiance distribution and horizontal visibility. Although the AOPs (sky and underwater radiance distributions and radiance and irradiance) were measured from the FLIP and the KM, these data were not collected concurrently with the IOPs. Therefore, the underwater radiance distribution was modeled from measured IOPs using the well-documented HydroLight model, which solves radiative transfer equations in water based on invariant imbedding theory [24]. Necessary inputs to HydroLight include the IOP and the boundary conditions. We assumed a twocomponent water body with pure water [25] as component 1 and particulate plus dissolved matter as component 2. The input IOPs were profiles of $a_{p g}(\lambda), c_{p g}(\lambda)$, and $b_{b p}(\lambda)$ that were measured directly during the RaDyO Santa Barbara Channel experiment. Phase functions were dynamically determined according to the measured backscatter fraction, $b_{b p}(\lambda) / b_{p}(\lambda)$, using Fournier and Forand [26] phase functions [27]. Inelastic scattering processes were not included in HydroLight runs. See Mobley [24] for more details on the HydroLight model.

HydroLight input boundary conditions include wind speed, solar angle, cloud cover, downwelling sky irradiance, and ocean bottom type. Input wind speed was provided by the KM meteorological data, averaged in time over the collection periods of the IOP profiles. Solar angle and cloud cover were set to $30^{\circ}$ and $0 \%$, respectively, and the RADTRAN model determined direct and diffuse components of irradiance [28]. We assumed optically deep waters, i.e., the ocean bottom reflectance is justifiably neglected. Computations were made at the $532 \mathrm{~nm}$ wavelength at every $5 \mathrm{~m}$ between the surface and $30 \mathrm{~m}$.

For the first-order model, we used the relationship presented by Davies-Colley [29] and further examined by Zaneveld and Pegau [30] (hereafter referred to as Z\&P03) to estimate the horizontal visibility of a black target, $y$ :

$$
y=4.8 / \alpha,
$$

where $\alpha$ is the photopic beam attenuation coefficient, which is a function of the spectral background radiance and the distance between the target and the observer. It is approximated by Z\&P03 [30]:

$$
\alpha=c_{p g}(532) * 0.9+0.081 .
$$

In this regard, only one of the IOPs, the beam attenuation coefficient at $532 \mathrm{~nm}$, is necessary for predictions of horizontal visibility of a black target.

In addition to the first-order Z\&P03 [30] visibility model [30], a backward vector Monte Carlo method [31] was used to calculate the underwater visibility. This method solves the vector radiative transfer equations in a coupled-atmosphere-ocean system when an underwater object is present and gives the radiance when a detector looks into the object 
from a position either above or below the ocean surface. In the model simulations, the sun was at the zenith. The atmosphere was assumed to be conservative with an optical depth of $\tau=0.25$. The atmospheric scattering is governed by the Rayleigh scattering matrix. For simplicity, the ocean surface was driven by a constant wind speed of $5 \mathrm{~m} / \mathrm{s}$ using the Cox and Munk [32] wave slope model. The same two-component model was used for a $20 \mathrm{~m}$ deep ocean. The IOP measurements used as inputs to the Monte Carlo simulations included profiles of $a_{p g}(\lambda)$ and $c_{p g}(\lambda)$. The $b_{b p}(\lambda) / b_{p}(\lambda)$ measurements were used to determine the FournierForand phase function, which analytically models the scattering due to particulate matter [27]. The reduced scattering matrix $\left(\tilde{P}_{i j}=P_{i j} / P_{11}\right)$ for the ocean is the same as that for Rayleigh scattering (e.g., see [31]). Since the vertical variance in $b_{b p}(\lambda) / b_{p}(\lambda)$ is very small, we assumed a single VSF, as determined by the average $b_{b p}(\lambda) / b_{p}(\lambda)$ throughout the whole water body. The ocean bottom was assumed to be nonscattering.

To study the horizontal visibility, a virtual round disk was vertically placed below the ocean surface as the target for Monte Carlo simulations. To be consistent with the Z\&P03 model [30], the disk was nonscattering by specifying a vanishing surface albedo. A virtual detector was placed at the same level, looking right into the target (the viewing zenith angle is $\left.90^{\circ}\right)$. We first calculated the visibility contrast $C_{v}(d)=\left(L_{B}(d)-L_{T}(d) / L_{B}(d)\right)$ as the detector moved away from the target, where $L_{T}$ and $L_{B}$ are the observed radiance of the target and of the surrounding background, respectively, and $d$ is the distance between the target and the detector. For a black target, $C_{v}(d)$ starts from 1 and approaches 0 when $d$ increases. The horizontal visibility was then determined when $C_{v}(d)$ drops to a threshold of 0.008 , considered the nominal contrast threshold for humans [33].

\section{Observations}

\section{A. Time Series}

A diurnal wind pattern was observed during the twoweek Santa Barbara Channel RaDyO experiment [Fig. 2(A)]. Winds were generally calm $(<4 \mathrm{~m} / \mathrm{s})$ in the mornings and increased to greater than $6 \mathrm{~m} / \mathrm{s}$, oftentimes reaching $10 \mathrm{~m} / \mathrm{s}$ by 1600 local time [Pacific Daylight Time (PDT)]. Starting in the afternoon of 15 September, winds greater than about $5 \mathrm{~m} / \mathrm{s}$ were sustained over the course of two days. The persistent winds resulted in increased upper water column mixing, as evidenced by the increase in $30 \mathrm{~m}$ temperature and salinity [Figs. 2(C) and 2 (D)] and the deepening of the MLD [Fig. 2 (A)].

Immediately following the high wind event, chlorophyll $a$ concentration increased from an average of about $1.4 \mu \mathrm{g} /$ liter to greater than $2 \mu \mathrm{g}$ /liter [Fig. 2(E)]. The variability of turbidity closely followed that of chlorophyll $a$ concentration, indicating that pigmented, organic material (e.g., phytoplankton) dominated the particles at the experiment site [Fig. 2(E)]. This was confirmed by laboratory analysis of particles in water samples collected from the $\mathrm{KM}$ over the duration of the $\mathrm{RaDyO}$ experiment [34]. The observed increase in phytoplankton could have been the result of wind-induced upwelling of nutrients (i.e., a local bloom) or advection of higher nutrient or biomass waters to the $\mathrm{RaDyO}$ field site.

The current magnitude at $17 \mathrm{~m}$ varied between nearly 0 and about $0.25 \mathrm{~m} / \mathrm{s}$ between 11 and 15 September [Fig. 2(B)]. The mean current magnitude at this time was $0.12 \mathrm{~m} / \mathrm{s}$; standard deviation was 0.06 $\mathrm{m} / \mathrm{s}$. Concurrent with increased wind speed, current magnitude increased to greater than $0.3 \mathrm{~m} / \mathrm{s}$ on 15 September, and generally higher current velocities were observed for the remainder of the experiment period; mean current velocity was $0.19 \mathrm{~m} / \mathrm{s}$ between 15 and 21 September. The maximum magnitude of current velocity $(0.39 \mathrm{~m} / \mathrm{s})$ was reached on 19 September, at which time wind speeds were greater than 10 $\mathrm{m} / \mathrm{s}$ and turbidity and chlorophyll $a$ concentration were high [about 100 counts and $3 \mu \mathrm{g} /$ liter, respectively—see Fig. 2].

\section{B. Profiles}

Optical profiles collected from the KM and FLIP indicate that waters were relatively clear over the

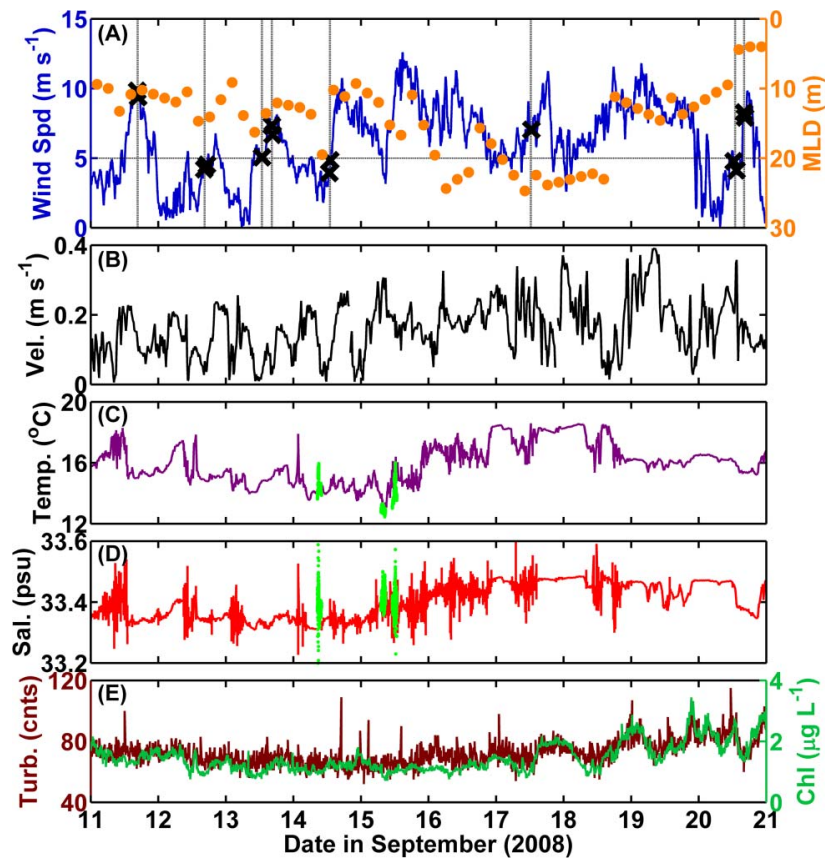

Fig. 2. (Color online) Time series of (A) wind speed (solid curve, 5 $\mathrm{m} / \mathrm{s}$ denoted by dashed horizontal line) and MLD (closed circles) and (B) magnitude of current velocity measured by the ADCP from the KM. The crosses and dashed vertical lines in (A) indicate concurrent KM and FLIP sampling periods, respectively. MLD was averaged to $4 \mathrm{~h}$ sampling rate. Time series of (C) temperature, (D) salinity, and (E) turbidity (dark) and chlorophyll $a$ concentration (light) measured at $30 \mathrm{~m}$ from the FLIP. The small closed circles in (C) and (D) are temperature and salinity, respectively, measured from the AUV at $30 \mathrm{~m}$ 
majority of the time period of the RaDyO field experiment. Average values of $c_{p g}(650)$ and $b_{b p}(657)$ were about 0.5 and $0.002 \mathrm{~m}^{-1}$ in the upper $20 \mathrm{~m}$ of the water column, decreasing to about 0.3 and $0.001 \mathrm{~m}^{-1}$ below $20 \mathrm{~m}$, respectively [Fig. 3]. The values of $a_{p g}(412)$ remained relatively consistent throughout the water column, with KM $a_{p g}(412)$ generally greater than FLIP $a_{p g}$ (412). Dissolved absorption at $412 \mathrm{~nm}$ increased with depth from an average of about 0.065 to $0.08 \mathrm{~m}^{-1}$. Profiles of the slope of the $c_{p}(\lambda)$ spectrum typically reflected a well-mixed region at the surface to about 15 to $20 \mathrm{~m}$. Values decreased in deeper water to $\sim 30 \mathrm{~m}$, suggesting an increase in average particle size [13]. At this depth interval, $n_{p}$ increased from average values of about 1.05 to 1.1, indicating a change from lower to higher particle density, which could be related to remineralization processes or a lower proportion of water-filled biological particles (Fig. $\underline{3}$, [14 $\underline{35}]$ ).

\section{Autonomous Underwater Vehicle Tracks}

Profiles of various properties collected by the AUV are shown in Fig. $\underline{4}$. The depth of the pycnocline during AUV operations was highly variable, ranging from 10 to $22 \mathrm{~m}$. The vertical distribution of turbidity was correlated with density, with more turbid waters overlying clearer waters, more or less separated by the pycnocline. Chlorophyll $a$ concentration derived from fluorescence measurements did not appear to be correlated to physical or hydrographic structure; chlorophyll $a$ distribution was likely controlled by factors such as historical light utilization and nutrient limitation. (Note that the chlorophyll fluorometer on the AUV was not intercalibrated with the fluorometer on the FLIP; absolute values of chlorophyll $a$ may not be accurate. We are concerned only with the variability of chlorophyll $a$ here.) Similar to profiles of $a_{g}(\lambda)$, the concentration of CDOM increased with increasing depth.

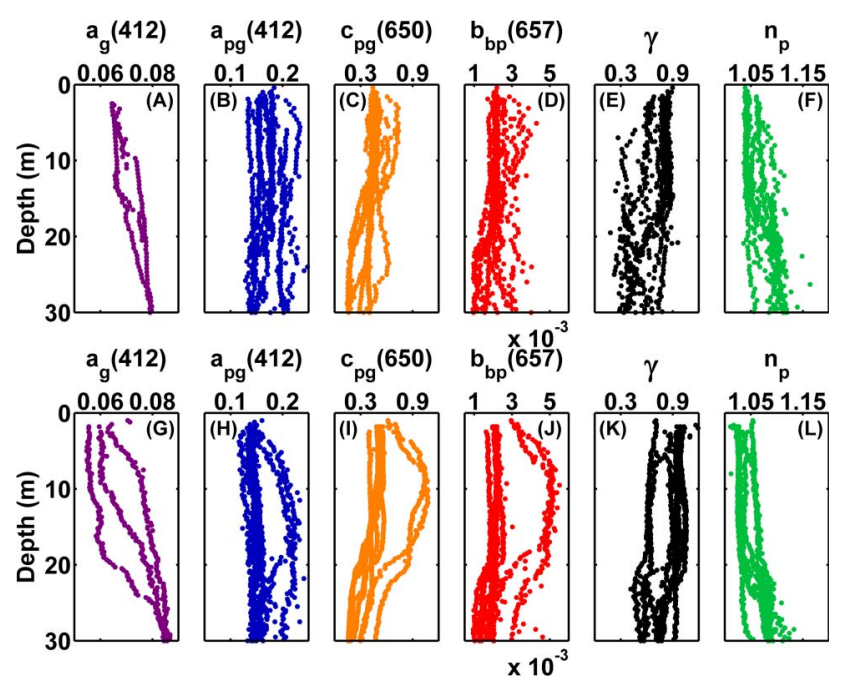

Fig. 3. (Color online) Vertical profiles of optical properties as a function of depth collected from the (A)-(F) KM and (G)-(L) FLIP. Data were binned to $0.25 \mathrm{~m}$. The units for $a_{g}(412), a_{p g}(412)$, $c_{p g}(650)$, and $b_{b p}(657)$ are $\mathrm{m}^{-1}$.

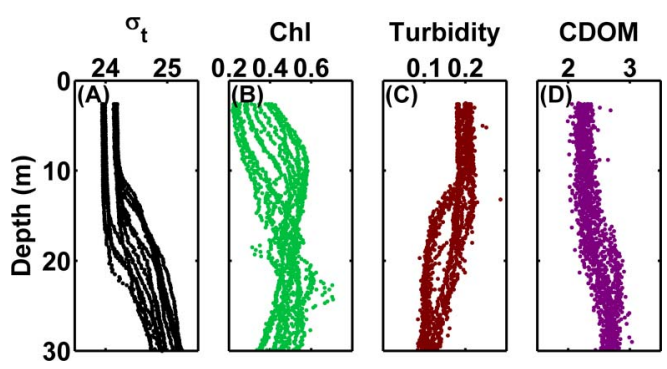

Fig. 4. (Color online) Vertical profiles of (A) density (kg/ m $\left.{ }^{3}-1000\right)$, (B) chlorophyll $a$ concentration $\left(\mu \mathrm{g} /\right.$ liter $\left.^{1}\right),(\mathrm{C})$ turbidity (NTU), and (D) CDOM concentration measured by the AUV during its expedition around the KM on 14 and 15 September 2008. Data were binned to $0.25 \mathrm{~m}$ and averaged over each side of the box traversed, i.e., over seven profiles.

\section{Results}

Percent differences [computed following Eq. (1)] between parameters measured from the KM versus those from FLIP as a function of $\sigma_{t}$ : temperature, salinity, $a_{g}(412), a_{p g}(412), c_{p g}(650), b_{b p}(657), \gamma$, and $\left(1-n_{p}\right)$ are shown in Fig. 5 . The percent differences between KM and FLIP temperature and salinity was minimal $(<0.5$ and $0.06 \%$, respectively) over the duration of the $\mathrm{RaDyO}$ field experiment, with temperature and salinity from the KM being generally greater in magnitude than hydrographic properties measured from FLIP [Fig. 5]. Optical properties exhibited more variability, with percent differences reaching $20 \%$ for $c_{p g}(650), b_{b p}(657)$, and $\left(1-n_{p}\right)$. Discrepancies between $a_{g}(412), a_{p g}(412)$, and $\gamma$ were on the order of $2 \%, 5 \%$, and $10 \%$, respectively. KMmeasured $a_{g}(412)$ and $a_{p g}(412)$ were greater than

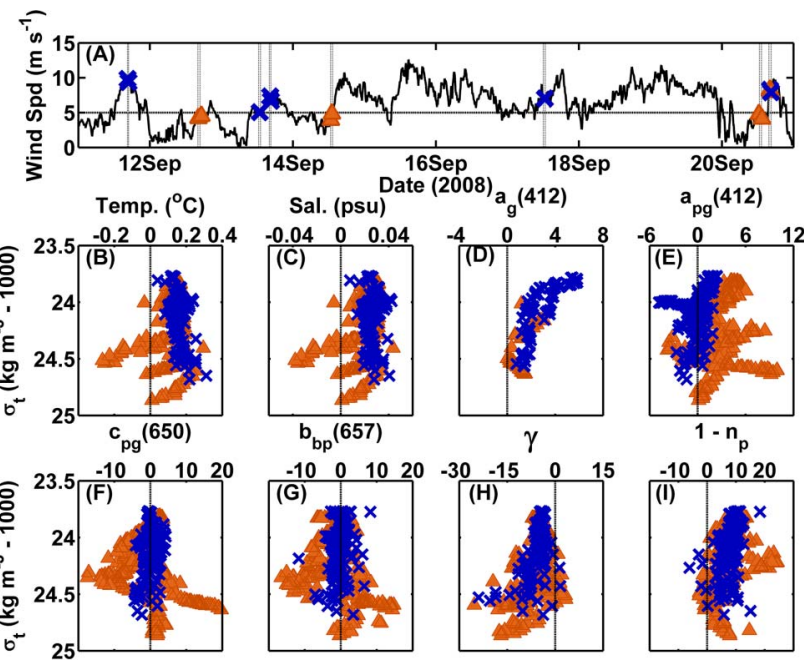

Fig. 5. (Color online) (A) Time series of wind speed collected from the Kilo Moana. Crosses and triangles indicate periods of KM optical profiler data collection. Light gray, vertical dashed lines denote concurrent KM and FLIP optical profiler data collection. (B)-(I) Profiles of percent differences between various properties measured from the KM versus from the FLIP as a function of density, $\sigma_{t}$. The units for $a_{g}(412), a_{p g}(412), c_{p g}(650)$, and $b_{b p}(657)$ are $\mathrm{m}^{-1}$. Crosses indicate periods of data collection with wind speeds $\geq 5 \mathrm{~m} / \mathrm{s}$, and triangles represent wind speeds $<5 \mathrm{~m} / \mathrm{s}$ (except the last profile). 
FLIP-measured $a_{g}(412)$ and $a_{p g}(412)$ nearest to the surface.

The vertical distribution of optical properties was more variable at the FLIP site as compared to the KM site [Fig. 3]. This resulted in increased percent differences between the two datasets during certain periods of the field experiment. The pattern of lesser and greater discrepancies between KM and FLIP measurements of temperature, salinity, $a_{p g}(412)$, $c_{p g}(650)$, and $b_{b p}(657)$ coincided with increased and decreased wind speeds. Other than the last profile, KM and FLIP profiles for these properties agreed well during periods with wind speeds greater than or equal to $5 \mathrm{~m} / \mathrm{s}$ and vice versa [Fig. 5]. The vertical variability of properties measured from the FLIP and $\mathrm{KM}$ was greater for wind speeds of less than $5 \mathrm{~m} / \mathrm{s}$. The last profile does not exhibit good agreement despite a relatively high wind speed; however, it closely follows a sharp increase in wind speed after a period of low wind speeds.

What caused the observed inconsistencies between KM and FLIP hydrographic and optical properties? We explore three potential sources of variability:

1. Instrumentation or sampling effects: different calibration and sampling protocols employed on the KM and the FLIP led to perceived horizontal variability in optical properties.

2. Platform effects: during low wind conditions, upper water column stratification at the FLIP site was destroyed by the hull of FLIP itself.

3. Environmental variability: tidally driven internal waves resulted in horizontal variability.

\section{A. Instrumentation or Sampling Effects}

Here, we investigate sources of error between properties measured from the KM and FLIP during periods of high winds only ( $\geq 5 \mathrm{~m} / \mathrm{s}-$ crosses in Fig. 5(A)]. The percent differences calculated for salinity and temperature during well-mixed periods were centered on $0.025 \%$ and $0.18 \%$, respectively [Fig. 5]. Stewart [36] reports an accuracy of $\pm 0.003 \mathrm{psu}$ (psu stands for practical salinity unit) for the relationship between conductivity and salinity in seawater, and Saunders [37] states an accuracy of 0.002 psu for a Sea-Bird $9 \overline{11}$ Plus CTD. Thus differences in salinity measured from the KM and FLIP during high wind conditions can be attributed to instrumental effects; discrepancies were within reported instrumental and salinity accuracy. The differences for temperature, although extremely small, should be noted because the values were greater than the manufacturerreported instrumental precision levels of $\pm 0.002{ }^{\circ} \mathrm{C}$. Temperature measured from the KM was generally greater than temperature measured from the FLIP. The reasons for this are unknown but can be attributed to either sensor calibration or sampling protocols or a combination of both. Between profiles, the FLIP profiling package was left in the water at $2 \mathrm{~m}$ depth, thereby keeping sensors close to ambient operating conditions. The KM profiling package was stored on the back deck of the vessel between samples, which could have resulted in slightly elevated temperatures recorded by the CTD. The differences in temperature did not significantly affect the derivation of $\sigma_{t} ;$ a $0.18 \%$ difference in temperature with salinity held constant resulted in a $0.03 \%$ difference in $\sigma_{t}$.

Further consistency checks were made between $\mathrm{KM}$ and AUV profiles of hydrographic properties. Five profiles of CTD data were collected concurrently aboard the KM and from the AUV. Because of differences in sampling methods (i.e., nearly stationary profiles from the KM versus undulating profiles from the AUV), the variance of each of the five profiles was computed for temperature, salinity, and density and compared. The results show that the variance in hydrographic properties compared well between the KM and AUV measurements (not shown). AUV variance was generally higher than $\mathrm{KM}$ variance, except for one profile. This is understandable, given the AUV covered a much greater horizontal sampling space than the KM. The variance of salinity was the most decorrelated of all properties, but direct comparisons reveal that differences were within instrumental precision and salinity accuracy levels.

The computed percent differences between KM and FLIP optical measurements are centered on $0 \%$ for $a_{p g}(412), c_{p g}(650)$, and $b_{b p}(657)$ [Fig. 5]. For profiles collected during well-mixed periods (winds $\geq 5 \mathrm{~m} / \mathrm{s}$ ), the discrepancies between KM and FLIP $a_{p g}(\lambda)$ and $c_{p g}(\lambda)$ were generally within reported instrumental operating precision $\left(\sim 0.002 \mathrm{~m}^{-1}\right.$; $[38,39])$. The percent differences computed for $\overline{a_{p g}}\left(\overline{\lambda)}\right.$ and $c_{p g}(\lambda)$ were not wavelength dependent (not shown). Differences in the backscattering coefficient, however, were higher for $470 \mathrm{~nm}$ (average of about $15 \%)$ as compared to $b_{b p}(657)$ and $b_{b p}(527)$ (mean of $3 \%$, which is the manufacturer-reported precision-not shown). This may have been due to either the linear interpolation of ECObb-9 to ECObb-3 wavelengths (recall that the blue-channel wavelength difference was $18 \mathrm{~nm}$ ) or calibration issues with the blue channel, or a combination of both. We were unable to perform bead calibrations on all ECObb sensors used for the RaDyO field experiment. This would have enabled better quantification of errors in measured $b_{b p}(\lambda)$.

The discrepancies in the slope of the $c_{p}$ spectrum, $\gamma$, during high wind conditions were, on average, about $-7 \%$ [Fig. 5]. These errors can be attributed to the measurement and modeling of $a_{g}(\lambda)$, which was subtracted from measured $c_{p g}(\lambda)$ to derive $c_{p}(\lambda)$. Recall that $a_{g}(\lambda)$ was measured only intermittently from the KM. For periods without direct measurements of $a_{g}(\lambda), a_{g}(\lambda)$ was modeled following methods described by Twardowski et al. [12], which determines a hyperbolic slope using least squares minimization. The amplitude and slope of $a_{g}(\lambda)$ were determined by inspection of measured $a_{g}(\lambda)$ and its relationship to $a_{p g}(\lambda)$, when available. Spectral dissolved absorption was measured consistently from the FLIP, and results show that the slope was quite variable 
[Fig. 6B-exponential slope shown]. Percent differences computed for the slope of $c_{p g}(\lambda)$ measured from the KM versus from the FLIP are on average 0\% (not shown) as opposed to the $-7 \%$ difference in $c_{p}(\lambda)$ slope. The errors in $\gamma(-7 \%)$ and $b_{b p}(527)(3 \%)$ contributed directly to the $20 \%$ difference in computed $\left(1-n_{p}\right)$ [Fig. $\left.\underline{5}(\mathrm{I})\right][\underline{14}$.

\section{B. Platform Effects}

The evolution of stratification at the RaDyO field site during and following the wind event discussed in Section 3 is illustrated in Fig. 7. The upper $30 \mathrm{~m}$ of the water column was well mixed at both the $\mathrm{KM}$ and FLIP sites during periods of elevated wind speed $(>7 \mathrm{~m} / \mathrm{s}$ ) observed on 17 September 2008. At the KM site, waters began to stratify shortly after wind speeds subsided on 20 September 2008. When wind speeds dropped to less than $5 \mathrm{~m} / \mathrm{s}$, a sharp halocline became evident in salinity profiles measured from the KM. This halocline first appeared in our observations at about $13 \mathrm{~m}$ geometric depth at 1225 PDT on 20 September and gradually moved up the water column to $11 \mathrm{~m}, 9 \mathrm{~m}$, and $6 \mathrm{~m}$ at 1256 , 1606 , and 1626 PDT on 20 September. However, a halocline was either nonexistent or was much deeper in the water column for salinity measured from the FLIP during the same time periods [Fig. 7]. Waters at the FLIP site remained well mixed until 1606 PDT on 20 September. At this time, the observed halocline depth from FLIP was approximately $20 \mathrm{~m}$ and it remained at this depth through the end of our observations.

Wind speeds had increased sharply at around 1600 on 20 September; this increase in winds did not appear to affect the evolution of stratification. However, it is hypothesized that a more gradual halocline (i.e., a change in salinity vertically over several tens of $m$ as opposed to over a few $\mathrm{m}$ as for a sharp halocline)
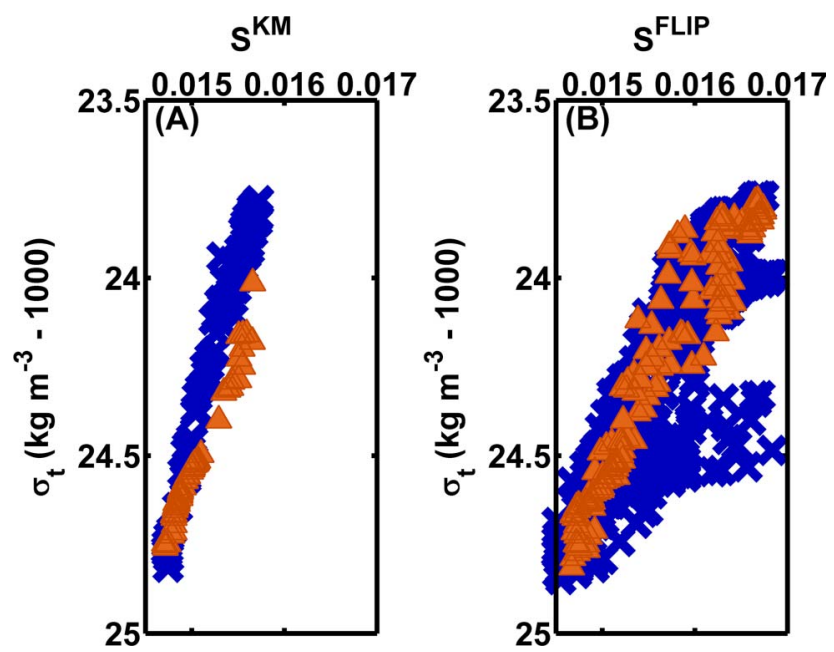

Fig. 6. (Color online) Vertical profiles of the exponential slope of the dissolved absorption coefficient, $S$, for (A) KM and (B) FLIP measurements of $a_{g}(\lambda)$. Crosses indicate data collected during periods of wind speeds greater than $5 \mathrm{~m} / \mathrm{s}$, and triangles denote data collected during periods of low wind conditions $(<5 \mathrm{~m} / \mathrm{s})$.

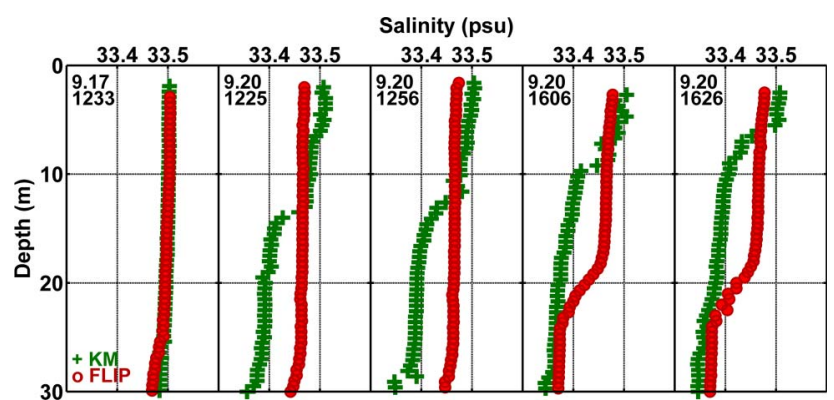

Fig. 7. (Color online) Profiles of salinity as a function of depth measured from the KM (pluses) and the FLIP (circles). Approximate dates and times of profile collection are indicated.

eventually formed at both sites after our sampling operations ceased at 1626 on 20 September. A gradual halocline was detected at both sites during afternoon diurnal winds during the earlier portion of the RaDyO experiment ( 1600 on 11 and 13 September-data not shown). The patterns seen in halocline depth were also seen in thermocline and pycnocline depths and during diurnal winds observed between 11 and 15 September (not shown). The halocline depth did not appear to be affected by variability observed in current velocity.

The vertical distribution of optical properties was similar to that of hydrographic properties. Figures $\underline{8}$ and $\underline{9}$ each show two sets of profile data; the upper panels show data that were collected on 17 September 2008 at 1233 PDT. The recorded wind speed at this
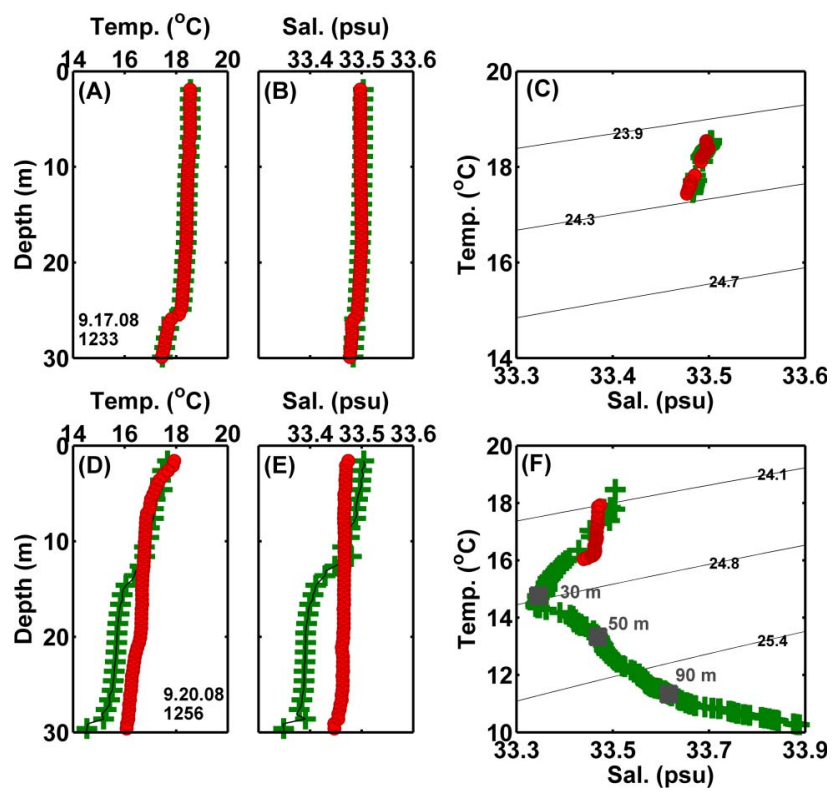

Fig. 8. (Color online) Vertical profiles of (A) temperature and (B) salinity as a function of depth (every other data point is shown); and (C) temperature-salinity plot collected on 17 September 2008 (wind speed $>7 \mathrm{~m} / \mathrm{s}$ ). (D)-(F) Same as (A)-(C) but for data collected on 20 September 2008 (wind speed $5 \mathrm{~m} / \mathrm{s}$ ). The temperaturesalinity plot in $(\mathrm{F})$ is from a deep cast showing the source of higher salinity water below $30 \mathrm{~m}$. Data from 30,50 , and $90 \mathrm{~m}$ depths are indicated with a gray square and are labeled. Pluses represent data collected from the KM, and circles denote data collected from the FLIP. Density contours are presented and labeled. 
time was greater than $7 \mathrm{~m} / \mathrm{s}$. The lower panels present data collected on 20 September 2008 at 1256 PDT, during wind speeds of about $4 \mathrm{~m} / \mathrm{s}$. The differences between the two time periods are apparent [Figs. 8 and 9]. Computed percent differences between optical properties are close to $0 \%$ over all observed $\sigma_{t}$ in the upper $30 \mathrm{~m}$ for the high wind condition [Fig. 9]. Discrepancies deviate substantially from zero during the low wind condition.

We describe here the vertical pattern in optical properties observed following the high wind event, during the period of increased chlorophyll $a$ concentrations [20 September 2008-Figs. 2 and $8(\mathrm{D}), 8(\mathrm{E})$, and $8(\mathrm{~F})]$. Near-surface $a_{g}(\lambda)$ magnitudes and exponential spectral slope, $S$, measured from the KM increased at this time, whereas profiles of $S$ from the FLIP remained similar in shape to other time periods [Fig. 6]. We hypothesize that the increase in $S$ at the KM site was due to increased photobleaching of aquatic dissolved materials [40], facilitated by particularly strong stratification and surface retention of dissolved materials. Using incubation experiments, Twardowski and Donaghay [40] found that the exponential slope of their measured absorption spectra increased as a function of radiation dosage, resulting in steeper $a_{g}(\lambda)$ in surface waters as compared to at depth. The variability in $S$ at the FLIP site was not affected by wind speed [Fig. 6], likely due to the continued mixing of the upper water column. Despite the relative increase in the magnitude of $a_{g}(412)$ (not shown) and $a_{p g}(412)$ measured from the KM, magnitudes of $c_{p g}(\lambda)$ and $b_{b p}(\lambda)$ were higher from the FLIP as compared to the KM on 20 September 2008 , similar to other periods of low wind speeds.
The peak in the magnitude of $c_{p g}(\lambda)$ and $b_{b p}(\lambda)$ was located deeper in the water column at FLIP as compared to at KM [Fig. 8(E) and 8(F)].

Our observations suggest that the hull of FLIP itself behaved like a giant stirring rod while moored at the RaDyO field site. The "FLIP effect" was not evident during periods with wind speeds exceeding $5 \mathrm{~m} \mathrm{~s}^{-1}$, as the upper $20 \mathrm{~m}$ of the water column (at least) was well mixed everywhere. However during lower wind speeds, the FLIP itself acted to destroy local stratification, and optical properties exhibited a different vertical distribution as compared to profiles from the KM. Recall that the hull of FLIP extends over $90 \mathrm{~m}$ down into the water column. It is important to mention that the mixing from FLIP's hull likely would not have been as strong or may not have occurred at all if the FLIP was operating in a free-drifting mode. A drifting spar buoy tends to ride with oceanic motion, thereby reducing or even eliminating the stirring rod effect.

\section{Environmental Variability}

Environmental conditions, such as biological or particle patchiness or internal waves, oftentimes result in small-scale (on the order of a $\mathrm{km}$ ) horizontal variability in a system. Internal waves have been observed in the Santa Barbara Channel during summer months (e.g., see [41]). These internal oscillations can act to vertically displace water column constituents and can result in variability of optical properties across small horizontal scales. However, qualitatively speaking, the variability caused by internal waves would likely not be seen across density contours, as

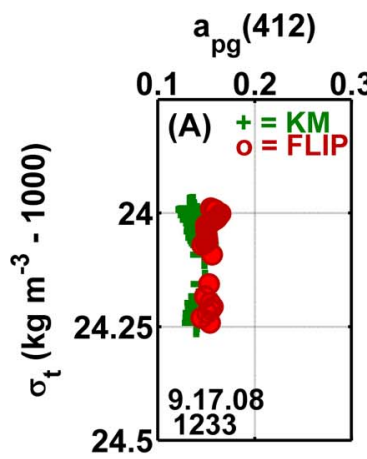

$\%$ Diff.
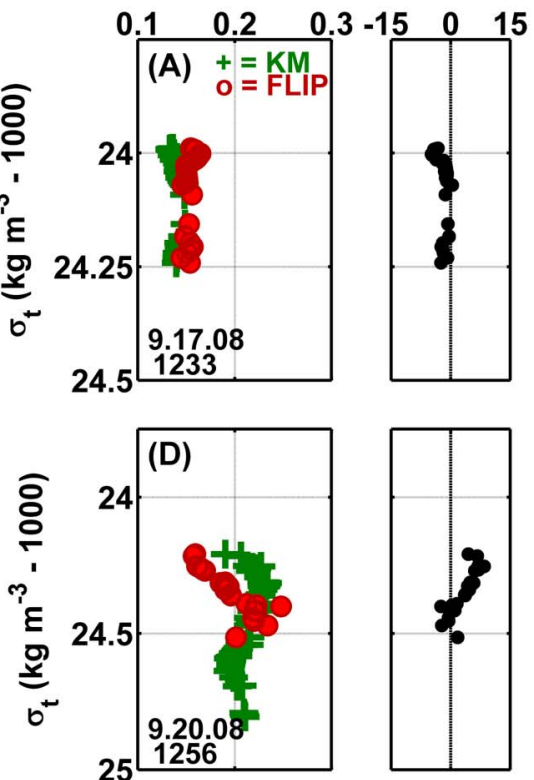

Fig. 9. (Color online) Vertical profiles of optical properties and computed percent differences between measurements from the KM and FLIP as a function of density, $\sigma_{t}$ for (A)-(C) wind speeds of greater than $7 \mathrm{~m} / \mathrm{s}$, measured on 17 September 2008 at 1233 and (D)-(F) wind speeds of about $4 \mathrm{~m} / \mathrm{s}$, measured on 20 September 2008 at 1256 PDT. Pluses represent KM data, and circles denote FLIP data. The units for $a_{g}(412), a_{p g}(412), c_{p g}(650)$, and $b_{b p}(657)$ are $\mathrm{m}^{-1}$. 
we observed between measurements made from the KM and FLIP during periods of low winds.

AUV data were used to quantitatively analyze the effects of environmental variability on the temporal and spatial patterns observed in optical properties. Variances were computed over time [Fig. 10(B)] and over vertical space [i.e., profiles-Figs. 10(B) and $10(\mathrm{C})$ ]. For example, the variance of temperature was computed as

$$
\sigma^{2}=\left[\sum(T-\mu)^{2}\right] / N
$$

where $T$ is temperature as a function of time or vertical space, $\mu$ is the mean of temperature over the time series or over a profile, and $N$ is the number of temperature data points collected over the time series or over a profile. It is expected that natural environmental variability would have resulted in consistently different variance computed for observations by the AUV as compared to observations from the FLIP and KM. We found, however, that the relationship in variances between data collected by the AUV and FLIP was highly dependent on wind conditions, with the variance for properties measured from the FLIP being more influenced by the winds.

Wind speed was, on average, $3.18 \mathrm{~m} / \mathrm{s}$ during the AUV operations on 14 September and $4.3 \mathrm{~m} / \mathrm{s}$ and $9.3 \mathrm{~m} / \mathrm{s}$ during the first and second box around the KM on 15 September, respectively [Fig. 10(A)]. Figure 10(B) compares the variance over time of hydrographic properties measured at $30 \mathrm{~m}$ by the AUV to $30 \mathrm{~m}$ WQM data collected from the FLIP during the time of AUV operations. Figures $10(\mathrm{C})$ and 10 (D) show variance over vertical space computed for each AUV profile compared to the average variance of FLIP profiles during low winds and high winds, respectively. The computed variance for all hydrographic properties measured from the AUV and the FLIP differed during low winds, with variance from AUV data greater than variance from FLIP data. Moderate winds resulted in variances that were similar to each other or variance in data collected from FLIP being less than variance in data collected from the AUV [Fig. 10(B)]. Variances were very similar to each other during high winds. The reason for the observed low variances for one AUV profile during low winds [Fig. $\underline{10}(\mathrm{C})]$ is unknown.

The computed variances were related to the intensity of the water column stratification, which was shown to be greatly influenced by the winds. Wind speed was not the only important factor influencing the computed variances; the rate of change of wind speed was also significant.

- Low winds. During and prior to the AUV operations on 14 September, wind speeds were less than $5 \mathrm{~m} / \mathrm{s}$. Winds increased slowly from about $2 \mathrm{~m} / \mathrm{s}$ to $4 \mathrm{~m} / \mathrm{s}$ and then dropped to $3 \mathrm{~m} / \mathrm{s}$ while the AUV was traversing its box around the KM. The AUV was measuring highly varying hydrographic proper-
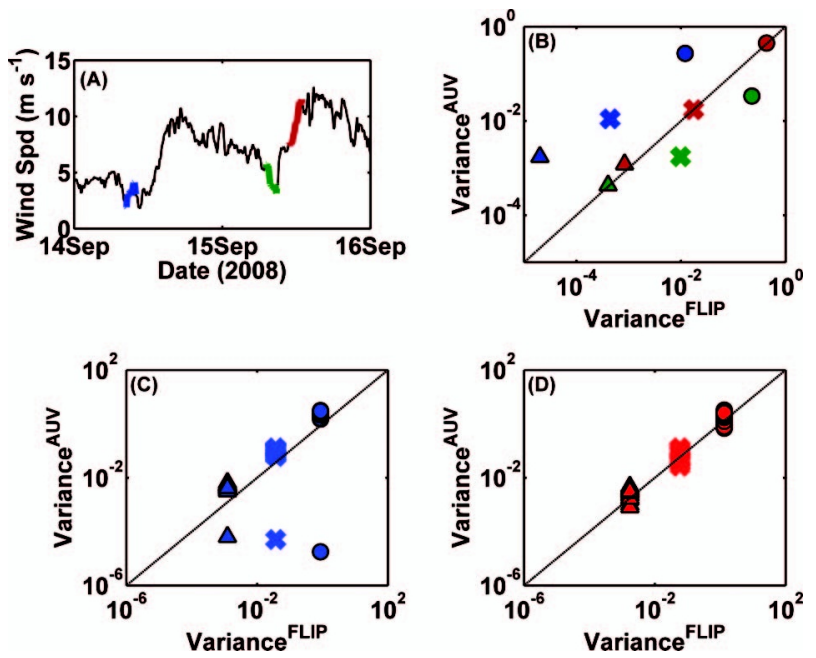

Fig. 10. (Color online) (A) Time series of wind speed measured aboard the KM from 14 to 16 September 2008. Blue, green, and red lines indicate the time periods of AUV sampling. (B) Computed variance from data measured by the WQM mounted at $30 \mathrm{~m}$ on the hull of FLIP versus data measured at $30 \mathrm{~m}$ by the AUV on 14 September (blue), 15 September at 0708 PDT (green), and 15 September at 1104 PDT (red). (C) Computed variance of the average of profiles from the FLIP during all periods when wind speeds were less than $5 \mathrm{~m} / \mathrm{s}$ versus the variance of each individual profile measured from the AUV during low winds. (D) Same as (C) except for during high wind conditions. Circles denote temperature, salinity is represented by triangles, and crosses symbolize density.

ties as it traversed, likely due to strong upper water column stratification. At the same time, however, FLIP results indicate much lower variance (more than an order of magnitude lower in most cases), perhaps due to local destruction of stratification from FLIP hull mixing effects and thus more constant values in hydrographic properties.

- Moderate winds. On 15 September, during the first traverse, winds decreased relatively rapidly from about $5.5 . \mathrm{m} / \mathrm{s}$ to 3.5 . Wind speeds were greater than $5 \mathrm{~m} / \mathrm{s}$ for more than $20 \mathrm{~h}$ prior to this decrease in winds. The water column was likely mixed, and then it began to stratify.

- High winds. During the second of the AUV operations on 15 September, the rate of change of wind speed was very large-winds increased from about $7.3 \mathrm{~m} / \mathrm{s}$ to $11.5 \mathrm{~m} / \mathrm{s}$. The water column was likely actively mixing during this time period, which resulted in common variance results at the AUV and FLIP sites.

Although AUV-observed variability in pycnocline depth due to internal waves is of sufficient magnitude to conjecture that internal waves may explain most of the observed IOP discrepancies between measurements from the KM and FLIP, the pycnocline measured from the FLIP was always deeper than that measured from the KM. Differences in temperature and salinity in the surface layers around the FLIP and KM sites also support the notion of active entrainment of deeper water and pycnocline erosion [Fig. 9]. 


\section{Discussion}

As expected, variable vertical distributions in optical properties can greatly impact the underwater radiance distribution and predictions of visibility. HydroLight-modeled underwater downwelling and upwelling irradiances $\left(E_{d}\right.$ and $\left.E_{u}\right)$, upwelling radiance $\left(L_{u}\right)$, remote sensing reflectance $\left(r_{\mathrm{rs}}=L_{u} / E_{d}\right)$, and radiance reflectance $\left(R=E_{u} / E_{d}\right)$ for high wind conditions $(\geq 5 \mathrm{~m} / \mathrm{s})$ and low wind conditions $(<5 \mathrm{~m} / \mathrm{s})$ are shown in Fig. 11. Percent differences between radiometric properties and AOPs [computed using Eq. (1)] during high winds were always less than $10 \%$ and generally less than $5 \%$. However, differences between radiometric properties during low wind, stratified conditions were $50 \%$ below and including $5 \mathrm{~m}$ depth. AOP discrepancies ranged from about $-20 \%$ nearest the surface, to $50 \%$ at $30 \mathrm{~m}$. The results suggest that models that are constructed using datasets of IOPs and SBL processes collected from a platform, such as the FLIP, could be significantly compromised, even though the FLIP has unique benefits for SBL characterization associated with being decoupled from surface wave motion. Additionally, field-based validation and inversion of such radiance-based SBL models could prove difficult and inaccurate.

We applied Eqs. (2) and (3) to $c_{p g}(532)$ data collected from the KM and FLIP durring low wind conditions and high wind conditions and examined the differences in predicted horizontal visibility. Low wind data were from three profiles taken on 20 September; wind speeds were about $4.5 \mathrm{~m} / \mathrm{s}$. High wind speeds were $5.07,6.68$, and $7.03 \mathrm{~m} / \mathrm{s}$ on 13 September at 1251 and 1636 and 17 September at 1233 , respectively. Predicted horizontal visibility at the KM and FLIP sites during high wind conditions were generally within
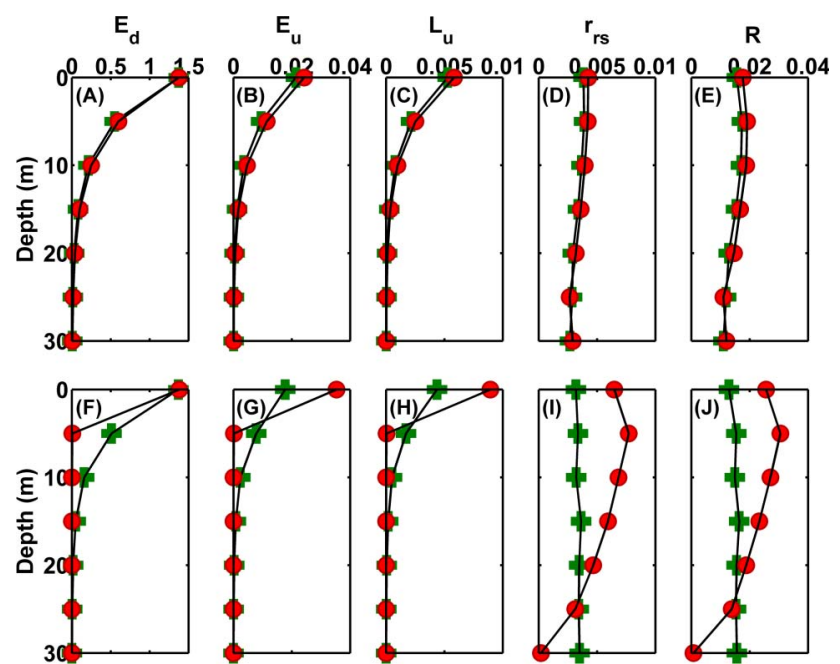

Fig. 11. (Color online) Vertical profiles of radiometric and apparent optical properties modeled using HydroLight during (A-E) high wind conditions on 13 September 2008 at 1251 PDT and (F-J) low wind conditions on 20 September 2008 at 1225 PDT. Pluses represent KM data, and circles denote FLIP data. Units for $E_{d}$ and $E_{u}$ are $\mathrm{W} \mathrm{m}^{-2} \mathrm{~nm}^{-1}$, for $\mathrm{Lu}$ are $\mathrm{W} \mathrm{m}-2 \mathrm{~nm}^{-1} \mathrm{sr}^{-1}$, and for $r_{\mathrm{rs}}$ is $\mathrm{sr}^{-1}$ ( $R$ is dimensionless).
$10 \%$ of each other, as expected with similar values of $c_{p g}(532)$ [Fig. 12].

The differences in the vertical distribution of $c_{p g}(532)$ during low wind; stratified conditions, however, contributed to differing predictions of horizontal visibility range at the KM and FLIP sites [Fig. 12]. As presented previously, beam attenuation coefficients were, for the most part, higher at the FLIP site when wind speeds were less than $5 \mathrm{~m} / \mathrm{s}$. Higher $c_{p g}(532)$ measured from the KM was sometimes observed below the $20 \mathrm{~m}$ depth. The different vertical distributions of $c_{p g}(532)$ resulted in a $10 \%$ $57 \%$ lower range of predicted horizontal visibility, with lower percent differences found near the surface and near $30 \mathrm{~m}$ and higher differences at intermediate depths. For example, on 20 September at 1225, $c_{p g}(532)$ measured from the KM and FLIP was 0.75 and $1.11 \mathrm{~m}^{-1}$, respectively, at about $18 \mathrm{~m}$. This difference resulted in computed horizontal visibilities of $6.38 \mathrm{~m}$ at the $\mathrm{KM}$ site and $4.44 \mathrm{~m}$ at the FLIP site. The largest discrepancies in predicted visibility were observed on 20 September at about a $20 \mathrm{~m}$ depth. Here, $y^{\mathrm{KM}}$ was predicted to be $6.5 \mathrm{~m}$ and $y^{\text {FLIP }}$ was computed to be $13 \mathrm{~m}$. This $6.5 \mathrm{~m}$ difference in predicted horizontal visibility range would result in grossly inaccurate estimates of probability of detection or probability of identification and hence, unsuitable performance optimization for, e.g., divers during commercial or military operations.

The horizontal visibility predicted by Z\&P03 [30] [Eqs. (2) and (3)], however, only depends on $c_{p g}(5 \overline{32})$, as this model effectively neglects higher-order contributions from multiple scattering processes. On the other hand, the Monte Carlo model has multiple scattering included. In this case, the scattering coefficient and the size of the target are also involved in the determination of the underwater visibility (detailed discussions of this topic will be presented in a separate study). Here we will focus on the differences between the predicted horizontal visibilities based on IOPs collected from the KM and FLIP. Since Monte Carlo computations are time consuming, we only calculated horizontal visibilities based on two sets of IOP profiles collected on (a) 13 September
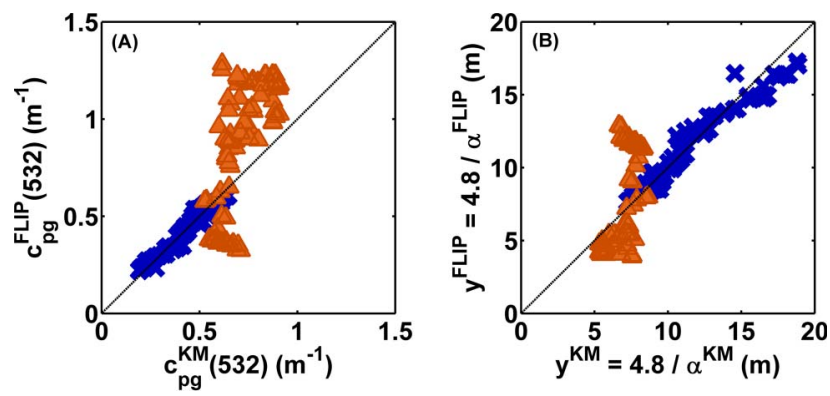

Fig. 12. (Color online) Comparisons between (A) beam attenuation coefficients ( $532 \mathrm{~nm}$ ) collected from the KM versus those collected from the FLIP (as a function of $\sigma_{t}$ ) and (B) computed horizontal visibility of a black target, $y$, using data collected from the KM versus from the FLIP. Crosses and triangles denote data collected during high wind and low wind conditions, respectively. 


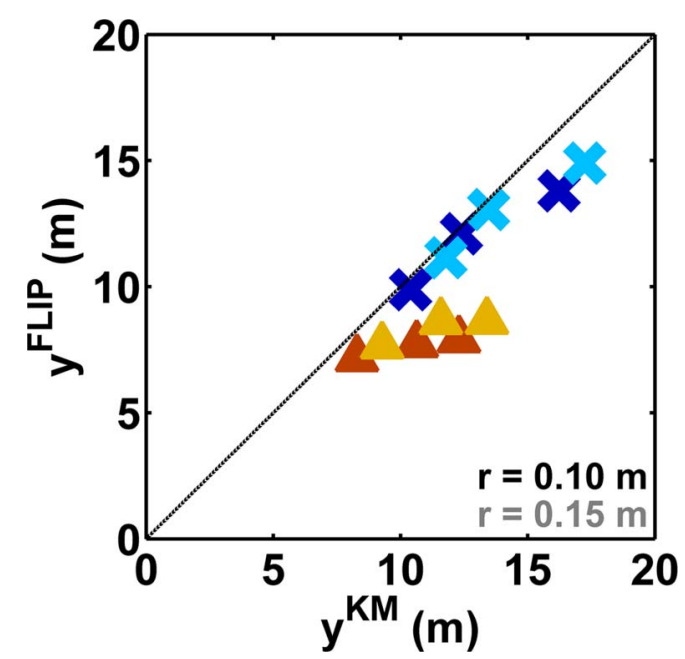

Fig. 13. (Color online) Comparison between computed horizontal visibility of a black target, $y$, using data collected from the KM versus from the FLIP. Crosses and triangles denote data collected during high wind and low wind conditions, respectively. Dark and light symbols signify results for targets with a diameter of 0.2 and $0.3 \mathrm{~m}$ (radius of 0.1 and $0.15 \mathrm{~m}$ ), respectively.

at 12:32 PDT that corresponds to high wind conditions where $c_{p g}(532)$ from the two sites were very similar and (b) 20 September at 12:35 PDT that corresponds to low wind conditions where $c_{p g}(532)$ at the FLIP site was greater in magnitude than at the KM. The target and detector were placed at the same level below the ocean surface, at three depths: 10,15 , and $20 \mathrm{~m}$. At each depth, the horizontal distance between the two was continuously varied from 0.1 to $20 \mathrm{~m}$. The visibility range was determined when the target disappears. To show the dependence of the horizontal visibility on the size of the target, targets with a diameter of 0.2 and $0.3 \mathrm{~m}$ were considered.

According to the Monte Carlo model, predicted visibility of a target with a finite size is greater than that given by the first-order model [Figs. 12 and 13], and a larger target is more visible than a smaller target [Fig. 13]. However, the percentage differences between Monte Carlo predictions at the two sites are similar to those given by the first-order model. Predicted visibility during high wind conditions were close to each other with percentage differences within $15 \%$, while those during low wind conditions show percentage differences of up to $45 \%$ [Fig. 13]. This suggests that the first-order model based on $c_{p g}(532)$ gives good approximations when the percentage difference is of concern.

\section{Summary}

The majority of observed hydrographic and optical variability between the KM and FLIP sites appeared to be the result of platform effects, as affected by wind speed. The hull of the FLIP acted to destroy local stratification during periods when wind speeds were less than $5 \mathrm{~m} / \mathrm{s}$. Differing vertical patterns in hydrographic properties and dissimilar vertical distributions of water constituents (and, therefore, opti- cal properties) observed between the KM and FLIP were the consequence of FLIP-induced mixing. The FLIP effect was not a factor during higher wind speeds, as the upper water column was well mixed at both platform locations. Note that the FLIP was moored during the Santa Barbara Channel RaDyO experiment. The FLIP in free-drifting mode, where it is allowed to ride with oceanic motion, may not have been as strongly affected by wind-induced mixing. Variability in optical products, $S, \gamma$, and $n_{p}$ were primarily a consequence of instrumentation effects; the spectral slope of $a_{g}(\lambda)$ at the KM site was more variable than assumed, which contributed to discrepancies in computed $c_{p}(\lambda), \gamma$, and $n_{p}$. Statistical analysis of AUV, KM, and FLIP data show that it is unlikely that environmental conditions over a horizontal scale of less than $2 \mathrm{~km}$ contributed to the consistent observed variability between KM and FLIP measurements.

The observed variable vertical distributions in optical properties greatly affected modeled underwater radiance distribution and predictions of horizontal visibility. HydroLight-modeled radiometric properties and AOPs differed by about $50 \%$ between the KM and FLIP sites during stratified, low wind conditions, as compared to less than $10 \%$ during well-mixed periods. The attenuation-based model presented by Zaneveld and Pegau [30] and a backward Monte Carlo model were used to predict the horizontal visibility of a black target for high wind and low wind conditions. Results from both models were consistent. Our results show that highly variable IOPs observed between the FLIP and KM during low winds can affect predictions of visibility by up to $57 \%$. Differences were less than $15 \%$ between KM and FLIP predicted visibility range during wellmixed periods.

This research is supported by the Office of Naval Research (ONR) Environmental Optics program as part of the Radiance in a Dynamic Ocean ( $\mathrm{RaDyO})$ project. The authors would like to thank Frank Spada, Ian Robbins, Megan Cimono, and the crews of the R/V Kilo Moana and R/P FLIP for their assistance with data collection.

\section{References}

1. S. Q. Duntley, "Light in the sea," J. Opt. Soc. Am. 53, 214233 (1963).

2. N. G. Jerlov, Optical Oceanography (Elsevier, 1976).

3. R. W. Preisendorfer, Hydrologic Optics (National Oceanic and Atmospheric Administration, 1976), Vol. 1.

4. G. R. Fournier and M. Jonasz, "Computer based underwater imaging analysis," Proc. SPIE 3761, 62-77 (1999).

5. G. W. Kattawar and M. J. Rakovic, "Virtues of Mueller matrix imaging for underwater target detection," Appl. Opt. 38, 6431-6438 (1999).

6. W. S. Pegau, D. Gray, and J. R. V. Zaneveld, "Absorption and attenuation of visible and near-infrared light in water: dependence on temperature and salinity," Appl. Opt. 36, 60356046 (1997).

7. J. M. Sullivan, M. S. Twardowski, J. R. V. Zaneveld, C. M. Moore, A. H. Barnard, P. L. Donaghay, and B. Rhoades, 
"Hyperspectral temperature and salt dependencies of absorption by water and heavy water in the $400-750 \mathrm{~nm}$ spectral range," Appl. Opt. 45, 5294-5309 (2006).

8. J. R. V. Zaneveld, J. C. Kitchen, and C. M. Moore, "Scattering error correction of reflecting-tube absorption meters," Proc. SPIE 2258, 44-55 (1994).

9. E. Boss and W. S. Pegau, "Relationships of light scattering at an angle in the backward direction to the backscattering coefficient," Appl. Opt. 40, 5503-5507 (2001).

10. J. M. Sullivan, M. S. Twardowski, P. L. Donaghay, and S. A. Freeman, "Use of optical scattering to discriminate particle types in coastal waters," Appl. Opt. 44, 1667-1680 (2005).

11. X. Zhang, L. Hu, and M.-X. He, "Scattering by pure seawater: effect of salinity," Opt. Express 17, 5698-5710 (2009).

12. M. S. Twardowski, E. Boss, J. M. Sullivan, and P. L. Donaghay, "Modeling the spectral shape of absorption by chromophoric dissolved organic matter," Mar. Chem. 89, 69-88 (2004).

13. E. Boss, M. S. Twardowski, and S. Herring, "Shape of the particulate beam attenuation spectrum and its inversion to obtain the shape of the particle size distribution," Appl. Opt. 40, 4885-4893 (2001).

14. M. S. Twardowski, E. Boss, J. B. Macdonald, W. S. Pegau, A. H. Barnard, and J. R. V. Zaneveld, "A model for estimating bulk refractive index from the optical backscattering ratio and the implications for understanding particle composition in case I and case II waters,” J. Geophys. Res. 106, 14,129-14,142 (2001).

15. A. E. Gill, Atmosphere-Ocean Dynamics (Academic, 1982).

16. M. A. Moline, S. M. Blackwell, B. Allen, T. Austin, N. Forrester, R. Goldsborogh, M. Purcell, R. Stokey, and C. von Alt, "Remote environmental monitoring units: an autonomous vehicle for characterizing coastal environments," J. Atmos. Oceanic. Technol. 22, 1797-1808 (2005).

17. M. A. Moline, D. L. Woodruff, and N. R. Evans, "Optical delineation of benthic habitat using an autonomous underwater vehicle," J. Field Robotics 24, 461-471 (2007).

18. M. A. Moline, S. M. Blackwell, J. F. Case, S. H. D. Haddock, C. M. Herren, C. M. Orrico, and E. Terrill, "Bioluminescence to reveal structure and interaction of coastal planktonic communities," Deep-Sea Res. Part II 56, 232-245 (2009).

19. M. A. Moline, K. J. Benoit-Bird, I. C. Robbins, M. SchrothMiller, C. M. Waluk, and B. Zelenke, "Integrated measurements of acoustical and optical thin layers II: horizontal length scales," Cont. Shelf Res. 30, 29-38 (2010).

20. I. C. Robbins, G. J. Kirkpatrick, S. M. Blackwell, J. Hillier, C. A. Knight, and M. A. Moline, "Improved monitoring of HABs using autonomous underwater vehicles (AUV)," Harmful algae news / UNESCO 6, 931-943 (2006).

21. S. M. Blackwell, M. A. Moline, A. Schaffner, T. Garrison, and G. Chang, "Sub-kilometer length scales in coastal waters," Cont. Shelf Res. 28, 215-226 (2008).

22. Y. Chao, Z. Li, J. D. Farrara, M. A. Moline, O. M. E. Schofield, and S. J. Majumdar, "Synergistic applications of autonomous underwater vehicles and the regional ocean modeling system in coastal ocean forecasting," Limnol. Oceanogr. 53, 22512263 (2008).
23. L. F. Hibler, A. R. Maxwell, L. M. Miller, N. P. Kohn, D. L. Woodruff, M. J. Montes, J. H. Bowles, and M. A. Moline, "Improved fine scale transport model performance using AUV and HSI feedback in a tidally dominated system," J. Geophys. Res. 113, C08036 (2008).

24. C. D. Mobley, Light and Water: Radiative Transfer in Natural Waters (Academic, 1994).

25. R. M. Pope and E. S. Fry, "Absorption spectrum (380-700 nm) of pure water. II. integrating cavity measurements," Appl. Opt. 36, 8710-8723 (1997).

26. G. R. Fournier and J. L. Forand, "Analytic phase function for ocean water," Proc. SPIE 2258, 194-201 (1994).

27. C. D. Mobley, L. K. Sundman, and E. Boss, "Phase function effects on oceanic light fields," Appl. Opt. 41, 1035-1050 (2002).

28. W. W. Gregg and K. L. Carder, "A simple spectral solar irradiance model for cloudless maritime atmospheres," Limnol. Oceanogr. 35, 1657-1675 (1990).

29. R. J. Davies-Colley, "Measuring water clarity with a black disk," Limnol. Oceanogr. 33, 616-623 (1988).

30. J. R. V. Zaneveld and W. S. Pegau, "Robust underwater visibility parameter," Opt. Expr. 11, 2997-3009 (2003).

31. P.-W. Zhai, G. W. Kattawar and P. Yang, "Mueller matrix imaging of targets under an air-sea interface," Appl. Opt. 48, 250-258 (2009).

32. C. Cox and W. Munk, "Statistics of the sea surface derived from sun glitter," J. Mar. Res. 13, 198-227 (1954).

33. H. R. Blackwell, "Contrast thresholds of the human eye," J. Opt. Soc. Am. 36, 624-643 (1946).

34. D. Stramski, Marine Physical Laboratory, Scripps Institution of Oceanography, University of California, San Diego, La Jolla, California, USA, 92093 (personal communication, 2008).

35. F. Nencioli, G. Chang, M. Twardowski, and T. D. Dickey, "Optical characterization of an eddy-induced diatom bloom west of the island of Hawaii," Biogeosciences, 7, 151-162 (2010).

36. R. H. Stewart, "Introduction to physical oceanography," http:// oceanworld.tamu.edu/resources/ocng_textbook/contents.html.

37. P. M. Saunders, "The accuracy of measurements of salinity, oxygen, and temperature in the deep ocean," J. Phys. Oceanogr. 16, 189-195 (1986).

38. M. S. Twardowski, J. M. Sullivan, P. L.Donaghay, and J. R. V. Zaneveld, "Microscale quantification of the absorption by dissolved and particulate material in coastal waters with an ac-9," J. Atmos. Ocean. Technol. 16, 691-707 (1999).

39. M. S. Twardowski, H. Claustre, S. A. Freeman, D. Stramski, and Y. Huot, "Optical backscattering properties of the "clearest" natural waters," Biogeosciences 4, 1041-1058 (2007).

40. M. S. Twardowski and P. L. Donaghay, "Photobleaching of aquatic dissolved materials: absorption removal, spectral alteration, and their interrelationship," J. Geophys. Res. 107, (2002).

41. E. E. McPhee-Shaw, D. A. Siegel, L. Washburn, M. A. Brzezinski, J. L. Jones, A. Leydecker, and J. Melack, "Mechanisms for nutrient delivery to the inner shelf: observations from the Santa Barbara Channel," Limnol. Oceanogr. 52, 17481766 (2007). 